The design and scale-up of spray dried particle delivery systems

Ali Al-Khattawi*1 ${ }^{1}$ Andrew Bayly ${ }^{2}$, Andy Phillips ${ }^{3}$, David Wilson ${ }^{3}$

$1 *$ (Corresponding Author)

Aston Pharmacy School

Aston University

Aston Triangle

Birmingham, UK B4 7ET

Phone: +44 (0) 1212044735

Email: a.al-khattawi@aston.ac.uk

2

School of Chemical and Process Engineering

University of Leeds

Leeds, UK LS2 9JT

3

AstraZeneca

F53/14 Etherow Building

Charter Way

Macclesfield, UK SK10 2NA 
The design and scale-up of spray dried particle delivery systems 


\begin{abstract}
:
Introduction:

The rising demand for pharmaceutical particles with tailored physico-chemical properties has opened new markets for the spray drying technology especially for solubility enhancement, improvement of inhalation medicines and stabilization of biopharmaceuticals. Despite this, the literature on spray drying is scattered and often not addressing the fundamental principles underpinning the robust development of pharmaceutical products. It is therefore necessary to present a clearer picture of the field and highlight the principles and factors influencing particle design and scale-up.
\end{abstract}

\title{
Areas covered:
}

The review firstly presents a systematic analysis of the trends in development of particle delivery systems using spray drying. This is followed by exploring the mechanisms governing particle formation and the transformations undergone in the various process stages. The next section highlights the particle design factors including those of different equipment configurations and feed/process attributes. Finally, the review summarises the current industrial approaches for scale-up of pharmaceutical spray drying.

\section{Expert opinion:}

The spray drying process provides the ability to directly design particles of the desired functionality. This is of great benefit for the pharmaceutical sector especially as product specifications are becoming more encompassing and exacting. One of the biggest barriers to the spray dried product translation remains one of scale-up/scale-down. A shift from the trial and error approaches of the past to fundamental model-based particle design approaches helps to enhance control over product properties. To this end, process innovations and advanced manufacturing technologies are also particularly welcomed. 
Keywords: Spray drying, particle design, drug delivery, scale-up, solubility, pulmonary, biopharmaceuticals, controlled-release

\section{Introduction}

The drive towards continuous processing and to design quality into products promises to streamline pharmaceutical manufacturing in the future [1,2]. Spray drying is an established continuous process that provides unique particle design capabilities. The control of particle size, morphology, crystallinity and surface texture/area via spray drying enables the design of sophisticated drug delivery systems [3-5]. The process also has regulatory recognition and is available in various configurations and manufacturing scales [6].

The development of particle delivery systems using spray drying requires an understanding of the engineering principles underpinning particle formation [7-9]. Complex interactions in the feed/process stages greatly influence particles' properties [10-14]. Furthermore, scale-up is a current challenge requiring a closer match between early clinical samples and the marketed product to attain bioequivalence [15]. Therefore, discussing the design and scaleup of pharmaceutical particle systems via spray drying is both timely and necessary to facilitate technology adoption.

It has been suggested that spray drying technology will continue to strengthen its position in the pharmaceutical industry and gain a growing share of the market in the coming years [16]. The analysis of 5853 spray drying articles produced from 1990-2016 showed that the number of research articles mentioning spray drying and drug delivery has seen 11-fold increase in 2010-16 compared to the 1990-99 period. This surge in the use of spray drying for drug delivery applications could be attributed to the rise of new challenges in the oral and pulmonary drug delivery fields as will be seen later in this review. 
Traditionally, spray drying is used in the pharmaceutical excipient industry to process multifunctional excipients e.g. for high-throughput production of microcrystalline cellulose or spray dried lactose [17]. Nevertheless, the last few years have seen new adopters of the technology especially in the UK pharmaceutical contract development and manufacturing organisation (CDMO) industry. The main driving markets are solubility (bioavailability) enhancement of poorly soluble active pharmaceutical ingredients (APIs), formulation of respirable drug delivery systems and the stabilisation of biopharmaceuticals (section 2).

The review will commence with a systematic overview of the particle delivery systems produced via spray drying. This will inform the following discussions on particle transformations and particle design factors. The mechanisms of particle transformations and some of the governing equations in each process stage will be discussed. Then, particle design factors influencing the product properties, namely: equipment configurations and feed/process control will be discussed. Finally, scale-up best industrial approaches will be highlighted. The goal of this review is to guide formulation scientists and process engineers through the available literature on spray drying whilst highlighting the fundamental principles underpinning the use of the technique. Nvivo Pro ${ }^{\circledR} 11$ software was used to classify the literature and filter it per user generated queries. These included keyword searches for the analysis of 5853 research article summaries published between 1990 and 2016.

\section{Particle delivery systems}

Spray drying has been used to design many particle delivery systems for various routes of administration (Figure 1). The systematic analysis of literature showed that $90 \%$ of all spray drying publications on drug delivery were focused on oral and pulmonary drug delivery research. The drug delivery systems which successfully reached the market were mostly oral 
solid dispersions e.g. for etravirine [18], ivacaftor [19], and telaprevir [20], pulmonary dry powder inhalers (DPIs) e.g. insulin [21] and tobramycin [22] and biological products e.g. a fibrin-sealant formulation comprising fibrinogen and thrombin to control bleeding during surgery [23].

The number of pulmonary drug delivery applications of spray drying surpassed oral drug delivery applications during 2000-09. However, this has changed by 2010 with each of oral and pulmonary routes having almost equal share $(45 \%$ each) of the publications on drug delivery (Figure 1). On the other hand, the number of publications discussing spray drying use for parenteral drug delivery was steady over the last 26 years. It is also interesting to find applications of spray drying in emerging areas of drug delivery e.g. nasal, buccal routes.

For oral drug delivery, the fastest growing application of spray drying was solubility enhancement followed by achieving controlled release kinetics (Figure 1 A). For pulmonary drug delivery, the fastest growing application was improvement of aerosolization (aerodynamic) properties followed by solubility enhancement and achieving controlled release kinetics (Figure 1 B). These applications will be discussed in the next few sections.

\subsection{Solubility enhancement}

Spray drying is an effective option for the solubilisation of even practically insoluble APIs e.g. Telaprevir which has lower solubility than marble [20]. The rapid nature of the process makes it ideal to produce an amorphous form of a crystalline poorly soluble API [24]. The amorphous API produced by spray drying has better apparent solubility which helps to improve its dissolution and eventually enhance drug bioavailability. Nevertheless, it is unusual to find a spray dried amorphous API which is not in combination with other excipients e.g. Hydroxypropyl Methylcellulose Acetate Succinate (HPMCAS) or Polyvinylpyrrolidone (PVP) [25]. These are required for further improvement of the 
solubility and to stabilise the metastable amorphous API against re-crystallisation during storage [24]. Figure 2 shows the development of spray drying solubility enhancement technologies over the years.

The main 3 formulation types used for solubility enhancement via spray drying were solid dispersions, complex formation, and emulsified/self-emulsified drug delivery systems. The main technologies used since 2000 were solid dispersions and complex formation. In solid dispersions, the poorly soluble API and a hydrophilic polymeric carrier are dissolved or made miscible within a common solvent (usually organic volatile solvent). This is then spray dried to form a 'solid solution' where the drug is solubilised within the hydrophilic carrier polymeric chains in the solid state $[25,26]$. Therefore, the apparent solubility increases due to better wettability induced by the hydrophilic polymer and the amorphous form of the API after the process. Paudel et al. [25] reviewed the development of spray dried solid dispersions thoroughly. These formulations showed 5-3600 fold enhancement in solubility for various molecules e.g. phenytoin, curcumin etc. [27, 28].

Complex formation involves the molecular association of a poorly soluble API to water soluble molecules such as Cyclodextrins, or formation of a soluble salt using counter-ions. Spray drying usually helps in turning these complexes into flowable powders ready for filling or further processing. Cyclodextrin can impart better solubility by entrapping the poorly soluble API within its hydrophobic core while exposing hydrophilic moieties to the aqueous environment $[29,30]$. Salt formation improves the dissolution rate of the poorly soluble API via improving the apparent solubility in the diffusion layer/microenvironment surrounding the solid [31].

Emulsified/self-emulsified drug delivery systems developed by spray drying increased in popularity since 2010 . These formulations involve the emulsification of a poorly soluble API 
in a cocktail of oil and surfactants followed by spray drying to form a powder that can be administered in an oral solid dosage form e.g. tablets or capsules. Upon administration, the formulation self-emulsifies i.e. reconstitutes back as a liquid emulsion containing the solubilised API in the aqueous gut environment. Different types of these systems were reported in literature including solid self-microemulsifying and self-nanoemulsifying drug delivery systems (S-SMEDDS and S-SNEDDS) [32, 33].

Other less common solubilisation technologies developed using spray drying were surface modification of the API with a hydrophilic material and surfactants such as hydroxypropylmethyl cellulose (HPMC) and D-alpha-tocopheryl polyethylene glycol 1000 succinate (TPGS) to increase wettability [34], micronization to increase surface area available for dissolution [35] and co-crystal formation [36].

\subsection{Optimising aerosolization performance}

Spray drying is a key processing technique mainly for DPIs and occasionally for pressurised metered dose inhalers (pMDIs) [3]. For inhalation, it is desirable that particles have low density $<0.4 \mathrm{~g} / \mathrm{cm}^{3}$ and simultaneously small aerodynamic diameter, $d_{a}$, of approx. $2-4 \mu \mathrm{m}$ to allow deep lung deposition [37] (See section 4.2.2 for the relation of $d_{a}$ to particle geometric diameter $d_{g}$ ). Particles with $d_{a}>10 \mu \mathrm{m}$ predominantly deposit in the mouth and throat whereas particles with $d_{a}<1$ remain suspended in the air flow and are eventually exhaled $[37,38]$. At the same time, the particles should be dispersed easily upon patient inhalation of the dose which is a big challenge. Optimisation of these aerosolization properties via constructively designing particles with the required size, density and surface properties represents the fastest growing application of spray drying in pulmonary drug delivery (Figure $1 \mathrm{~B}$ above). 
Scientists devised two main spray drying strategies to create drug particles with $d_{a}$ of 2-4 $\mu \mathrm{m}$ whilst retaining good dispersion/flowability. The first is a Carrier strategy in which a fine API particle is attached onto the surface of a coarse carrier particle such as lactose or mannitol. This helps to improve the flowability and de-agglomeration of the API during filling/dispersion, while allowing the API to detach from the carrier and continue its journey to the deep lungs [39]. An alternative carrier approach is to fabricate nanoparticles of the API which are aggregated into a micron sized inhalable microsphere dubbed nano-micro composites. These aggregates of nanoparticles retain sufficient porosity (i.e. small $d_{a}$ ) allowing them to travel deeply in the lungs, whilst also showing good dispersion properties due to their combined micron size in the carrier [40].

The second strategy is a Carrier-Free one, where a relatively large API particle $(>5 \mu \mathrm{m})$ e.g. $10-20 \mu \mathrm{m}$ in $d_{g}$ is produced via spray drying [41]. This is with the condition that $d_{a}$ is between 2-4 $\mu \mathrm{m}$ through generating hollowness and/or porosity in the produced particle [42]. The larger $d_{g}$ gave the added advantage of diminished engulfing of inhaled particles by macrophages [43]. Spray drying can be used to create low density hollow or porous particles depending on feed and process factors $[3,5,12,44]$ as will be discussed later in section 4.2.

\subsection{Controlled release}

Spray drying was traditionally used to develop various microencapsulated or matrix based controlled release particle systems [45]. The literature showed that most spray dried controlled release systems were designed to achieve sustained or delayed drug release. The number of sustained release applications was significantly higher than delayed release applications (39 publications compared to 9), because of the wider spectrum of benefits the former brings to parenteral, pulmonary, and oral drug delivery. 
Various polymeric and film forming materials were used to encapsulate APIs and achieve a sustained release profile such as Poly(lactide-co-glycolide) (PLGA), Poly(vinyl alcohol) (PVA) [46], Chitosan [47] and Bovine serum albumin (BSA) [48]. The developed microspheres showed different release kinetics ranging from e.g. bi-phasic immediate followed by sustained release to Higuchi type long term sustained release [49-52]. The main applications of these systems were to achieve sustained drug release for pulmonary delivery e.g. for insulin [41] and to maximize therapeutic effect from surgical implants e.g. intracranial implant releasing paclitaxel over 28 days [53]. Few oral drug delivery applications were also found e.g. multi-particulates using methacrylic acid matrix polymer to sustain the release of Ferulic acid [54]. In recent years, combinations of polymeric sustained release systems e.g. chitosan-coated PLGA microspheres, were investigated to avoid macrophage uptake, and enhance the efficacy of anticancer drugs for local lung delivery [55].

Most delayed release drug delivery systems developed by spray drying used a $\mathrm{pH}$-triggering release mechanism. In general, the principle behind these systems is to create an insoluble matrix concealing the API until the delivery system reaches the ionisation $\mathrm{pH}$ of the polymer where it dissolves to release the API e.g. polymethacrylate delayed release polymer for intracellular delivery into the phagosome [56].

\subsection{Stabilisation of biopharmaceuticals}

Spray drying performance is often compared to freeze drying when used for the drying and stabilisation of biopharmaceuticals. Freeze drying is a lengthy batch process where the final product is presented as a powder cake [57]. On the other hand, spray drying is a rapid continuous process with the capability to engineer particle properties. The process is also 4-7 times cheaper than freeze drying considering the capital and operational costs [58]. The spraying (atomisation) element of the spray drying process is essential for its advantageous 
particle engineering capability (See sections 3.2 and 4.1). For this reason, recent efforts have re-evaluated the use of spraying as a particle engineering step prior to traditional freeze drying in a process dubbed 'spray freeze drying' [59].

The process of spray drying is sometimes viewed as a harsher method than freeze drying for drying heat-sensitive compounds such as biopharmaceuticals $[15,60,61]$. However, the overwhelming literature evidence confirms suitability of the technique for drying heatsensitive compounds [7, 10, 45, 62-67]. Evaporative cooling during the initial rapid drying process, short residence times and the use of co-current process layout minimize temperature exposure and create milder drying conditions $[7,65]$. The inclusion of stabilising excipients such as trehalose, lactose, polyols, inulin, polysorbate- 80 etc. further reduces potential denaturation. These excipients stabilise proteins via a number of mechanisms discussed in literature $[61,68,69]$, most notably through their ability to substitute for the sudden loss of hydrogen bonding between the protein and its hydration shell, therefore providing structural stability [70]. Furthermore, careful optimization of the drying conditions such as temperature and residence time $[71,72]$ helps to reduce the temperature 'felt' by the drying material. Moreover, solvent evaporation during the initial stages of drying leads to cooling of the droplets and their surrounding gas environment. The latter is very useful in preventing particle degradation near the harsh inlet conditions. For more information on the spray drying stages see section 3. It is noteworthy that a considerable number of proteins and other heat-sensitive compounds were successfully spray dried during the last decade e.g. probiotic cells, nitrogen-fixing bacteria [73], insulin, bovine serum albumin [74], plasma coagulation proteins fibrinogen and thrombin [23] and influenza antigen vaccine [69].

In recent years, the technique of aseptic spray drying has re-emerged for the drying of biopharmaceuticals $[23,75]$. The main advantage offered by spray drying under aseptic 
conditions is avoiding the terminal sterilization conditions that potentially denature biopharmaceuticals.

\section{Particle transformations during spray drying}

Spray drying is one of few techniques that can be used for rational design of particles for drug delivery applications. Particle design can be accelerated through better understanding of the key particle transformations taking place during the different stages of spray drying.

A typical co-current spray dryer operation in the pharmaceutical industry includes 4 main stages 1) feed, 2) atomisation, 3) drying and 4) product recovery stages (Figure 3). The figure highlights the main particle transformations expected in each stage.

\subsection{Feed stage}

Although the feed stage is a preparatory phase to the process, it has a significant impact on the final particle properties and care must be taken to understand any, desired or undesired, chemical or physical transformations that might occur. For example, the feed materials may undergo phase changes such as premature crystallization from solution due to high concentration or low temperature conditions outside the dryer [36]. They may also suffer from chemical incompatibility and degradation if solutions are left standing for a long time. Furthermore, one of the most important interactions in the feed is that of the solute and solvent. Solvent selection not only affects solubilisation of the API or excipients but also the final particle size, morphology, and phase structure through its effect on the evaporation rate $[3,11,25,76-79]$. The solvent effect could be better understood after discussing the Péclet number concept in the drying stage (section 3.3).

The solute diffusion rate within a drying droplet is related to the rheological properties of the feed. The diffusivity of the solute can be estimated via Stokes-Einstein equation (Equation 1) 
which shows that the viscosity, $\mu$, and hydrodynamic diameter, $d_{H}$, are inversely related to solute diffusivity, $D$.

$$
D=\frac{k T}{6 \pi \mu d_{H}} \ldots \ldots \ldots \ldots \ldots \ldots \text {.......... }
$$

(Where $k$ is Boltzmann's constant $\left(1.38 \times 10^{-23} \mathrm{~J} / \mathrm{K}\right)$ and $T$ is temperature).

The diffusivity (i.e. diffusion rate of feed components) could influence the formation of hollow or dense particles as will be explained later in the drying stage (section 3.3) using the Péclet number. Furthermore, the visosity and molecular weight of feed components could impact the pumping and atomisation process e.g. a highly viscous grade of HPMC potentially dries into filament-like particles instead of spherical particles because of the difficulty to break the highly viscous polymeric sheets into droplets. The sprayability of feed using twofluid atomisers can be explored by comparing the relative magnitude of viscous, surface tension and inertial forces which are captured by the Weber, We, Ohnesorge, $O h$, and Reynolds, $R e$, numbers [80]. These are dimensionless groups that help to characterise droplet breakup and the regions within atomisation e.g. dripping, jet, full atomisation, based on feed viscosity and velocity during atomisation [80].

\subsection{Atomisation stage}

Atomisation involves disintegration of the feed into droplets creating a high surface area for rapid drying. The liquid feed is atomised into droplets via different mechanisms e.g. pneumatic, mechanical, electrical, or sonic. In most atomisers, the liquid jet leaving the nozzle orifice firstly forms into a sheet which is broken down by shear forces and instabilities into ligaments and subsequently forms into droplets [80]. The latter phenomena are often described as the 'Wave Mechanism' in atomisation literature [81]. The turbulent nature of atomisation and instabilities occasionally lead to unconventional droplet/particle 
morphologies such as filament-like, pear-shaped or even mushroom-like particles [65, 82]. Some of the larger drops may undergo additional instability forming smaller droplets. In fact, the opposite could also occur as the smaller drops tend to coalesce or agglomerate [83]. Due to the complexity of droplet formation, droplet size is difficult to predict but can be measured experimentally using different methods discussed in Lefebvre [80]. Some of these methods such as laser diffraction or phase doppler measurements could be integrated into the process as process analytical technology (PAT) tools to monitor droplet evolution. Nevertheless, if droplet size, $d_{d}$, calculation is necessary, it can be estimated from dried particle size, $d_{P}$, using a simple theoretical mass balance (Equation 2).

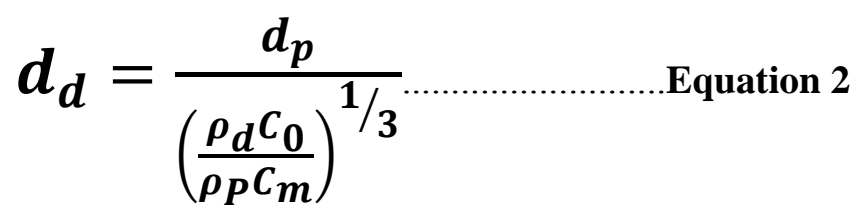

The above equation requires the prior knowledge of the dried particle size, droplet density $\rho_{d}$ (equivalent to feed density), feed solids concentration, $C_{0}$, dried particle density, $\rho_{p}$ and dried particle solids concentration, $C_{m}$. The assumptions attached to this equation are that particles are spherical and each particle is formed from a single droplet. In practice, the formation of shrivelled or buckled particles may underestimate the calculated droplet size and give inaccurate results due to loss of sphericity.

\subsection{Drying stage}

In the drying stage, typically, the atomised droplet temperature rapidly changes from its initial temperature to an equilibrium temperature, its wet bulb temperature, due to evaporative cooling. Once at this temperature the droplet dries steadily. This period is often called the constant rate period as the surface of the droplet remains saturated with solvent and the evaporative flux remains constant. As the droplet dries further the transport of solvent to the 
droplet surface is hindered via decreasing solvent diffusivity and/or solids formation, consequently the evaporative cooling decreases and the temperature increases continuously. The dried solids formed are either crystalline or an amorphous precipitate.

The formation of crystalline or amorphous solids is difficult to ascertain without experimental effort, however, simple empirical rules such as those of Mahlin and Bergström [84] could be used in a strictly indicative manner. The latter found that the glass forming ability of materials could be correctly predicted based on the molecular weight for $90 \%$ of the evaluated APIs in their study. Their conclusions showed that as a 'rule of thumb', drugs with a molecular weight more than $300 \mathrm{~g} / \mathrm{mol}$ are expected to be converted to the amorphous state using standard process technology (including spray drying).

Spray dried particles exhibit a huge variety of morphologies. These morphologies depend on both the material characteristics during drying, i.e. thermodynamic and material properties in solution, semi-dried and dried state, and on the drying conditions, initial solvent concentration and droplet size. A critical factor in the determination of many of these morphologies is when, and whether, the surface dries to form a shell. The formation of a shell (crust or film) is possible if the solids/solute concentration at the surface is high compared to the bulk. The dimensionless number, the Péclet number, $P e$, is a useful guide to whether this surface enrichment is possible. The Peclet number is generally defined as a ratio between mass transfer due to convection/advection, represented by a characteristic velocity, $u$, to that due to diffusion represented by the diffusivity divided by a characteristic length, $D / L$. In the case of a drying droplet, it represents the ratio of the velocity of the receding droplet surface, $|\mathrm{dr} / \mathrm{dt}|$, which is leading to an increase in concentration at the surface, to the diffusive velocity of the solute or suspended particles, $D / r$, which the concentration gradient is driving away from the surface (Equation 3). $D$ is the solute diffusion coefficient and $r$ is the droplet radius. 


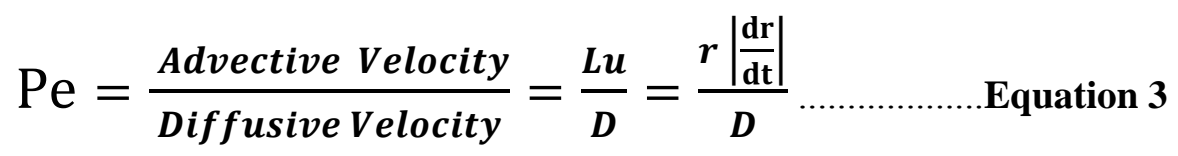

This equation is often written in terms of an evaporation rate, or flux, $\kappa$, which can be defined when $r d r / d t$ is constant and the surface area of the droplet linearly decreases with time [13].

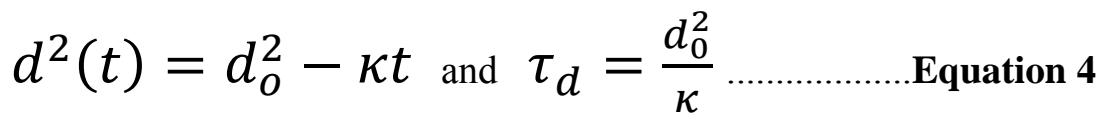

Where $\tau_{d}$ is a theoretical droplet drying time, $d$ is the droplet diameter and $d_{o}$ the initial droplet diameter and

$$
\frac{d\left(d^{2}\right)}{d t}=-\kappa=8 r \frac{d r}{d t}
$$

Consequently

$$
\mathrm{Pe}=\frac{\kappa}{8 D} \ldots \ldots \ldots \ldots \ldots . . . . . \text { Equation } 5
$$

As shown schematically in Figure 4, if the conditions inside the dryer allow rapid solvent evaporation rate $\uparrow \kappa$, the velocity of the receding surface is faster than the solute/solvent can diffuse away from it, i.e. Pe $>1$, resulting in accumulation of solids/solute at the surface and the potential for shell formation. Conversely, if the conditions result in a lower evaporation rate $\downarrow \kappa$, the solute which is accumulating at the surface is redispersed by diffusion towards the centre of the droplet $\uparrow D$ i.e. $\mathrm{Pe}<1$, and shell formation will not occur (Figure 4).

It is noteworthy that $\mathrm{Pe}$ is not the sole criterion for shell or dense particle formation and other factors (depending on the system under consideration) such as initial feed concentration, surface activity and solubility level for dissolved systems or the solids concentration, size and inter-particle forces for suspended systems may also determine the particle structure. Some of these factors are discussed below in section 4.2. 
Shell formation represents a strong barrier to solvent evaporation leading to increased local temperature in the droplet, occasionally above the boiling temperature $T_{b}$ of the solvent which causes build-up of internal pressure. Bubble nucleation also occurs if entrained gas is present in the droplet e.g. from atomisation stage [83]. Depending on the permeability and mechanical properties of the shell, the particle may relieve the pressure by inflation-deflation cycles (shrivelled or buckled particles), cracking (open hole or cracked particles), or even explosion (shattered particles). At the end, all liquid is evaporated and the particle reaches the outlet temperature $T_{\text {out. }}$ A more detailed analysis of temperature history of single droplets during drying can be found in Nešić and Vodnik [85], and Handscomb et al. [86].

\subsection{Product recovery stage}

The formation of deposits on the dryer walls represent one of the major factors affecting product recovery from spray drying. The unsteady gas flows experienced in the process are largely responsible for driving the particles towards the walls, particularly near the outlet pipes $[87,88]$. In many systems, the formation of deposits is initiated when the local temperature conditions i.e. outlet temperature, $T_{\text {out }}$, cause the droplet/particle surface temperature, $T_{\text {surface }}$, to exceed the glass transition temperature, $T_{g}$, of the materials by about $20^{\circ} \mathrm{C}$. When this happens, the materials transition from the highly viscous $\left(10^{12} \mathrm{~Pa} . \mathrm{s}\right)$ less sticky glassy state to the less viscous $\left(10^{6}-10^{8} \mathrm{~Pa} . \mathrm{s}\right)$ highly sticky rubbery state $[89,90]$.

This is exacerbated if the combined $T_{g}$ of the materials in the droplet is naturally low due to their high molecular mobility or hygroscopicity. The combined $T_{g}$ for two component mixtures could be found using the modified Gordon-Taylor equation (Equation 6, could be derived for $>2$ components) [24]:

$$
T_{g \text { mix }}=\frac{w_{1} T_{g 1}+K w_{2} T_{g 2}}{w_{1}+K w_{2}}
$$


Where $w_{1}$ and $w_{2}$ are the weight fractions of components 1 and 2, $T_{g 1}$ and $T_{g 2}$ are glass transition temperatures of components 1 and 2, and $K$ is a constant that could be calculated from the density $\rho$ and $T_{g}$ of components using Equation 7:

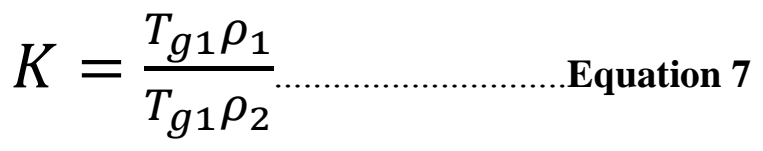

Therefore, it was suggested that when the viscosity of the droplet surface goes below a critical level of $10^{7}$ Pa.s, the material may remain as a syrup which has the tendency to stick even at low moisture contents [91]. On the other hand, a particle may bounce off the wall (rebound) if the conditions and material properties are well optimised, leading to minimal deposits.

Cyclones are ideal powder collection systems for pharmaceuticals [92] because they are efficient, easy to clean and widely available on both small and commercial scales. A cyclone is a conical shaped apparatus which separates particles by their inertia. Particles entering the cyclone with the gas stream follow its downward spiral path which throws them outward to the cyclone wall by their inertia. As a result, the particles may collide with the wall, lose momentum and become disengaged from the flow [93]. The solids continue to descend by sliding on the conical wall and are received in the collection bin. This main gas stream which carries the particles in a downward spiral is usually termed 'the main vortex'. However, at some point near the bottom of the cyclone cone 'the vortex end position' [94], the flow reverses itself travelling in an upwards spiral this time termed the 'inner' or 'core' vortex. This revered inner flow leads to the exit of the cyclone 'the vortex finder region' and carries lighter smaller particles out towards filters. That is why cyclones are generally not sufficiently effective at separating/collecting particles which are smaller than $5 \mu \mathrm{m}$ [95]. Powders of this size are required for pulmonary drug delivery applications (see section 2.2), 
hence, careful optimisation of the cyclone yield is sometimes necessary especially for amorphous or highly hygroscopic substances which already suffer from a stickiness issue as described earlier. Other collectors such as electrostatic precipitators may become more suitable for collecting much smaller particles in the nano-size range [95].

Cyclone performance is described by its collection efficiency and pressure drop which in turn depend on the velocity, solids concentration and pressure fields within the cyclone [93]. Each cyclone has a specific particle size range to collect above its cut-off diameter, D50. E.g. a cyclone with $D_{50}$ of $2 \mu \mathrm{m}$ is unable to capture $50 \%$ of particles $<2 \mu \mathrm{m}$ in size [10]. Pressure drop describes the resistance to gas flow in a cyclone [95, 96]. Pressure losses mostly dominate in the vortex finder and exit duct regions. Factors which decrease the strength of the vortex (indicated by a decrease in its tangential velocity) can cause a decrease in the cyclone pressure drop and vice versa [93]. Experiments have shown that increasing wall friction coefficient, concentration of solids, or length of the cyclone decrease pressure drop [93]. The use of narrow high-efficient cyclones was also reported to increase vortex strength (higher tangential velocity) thereby increasing pressure drop [96].

\section{Particle design factors}

The design of pharmaceutical particles using spray drying is influenced by equipment configuration and feed $\&$ process factors.

\subsection{Equipment configuration}

A strong link exists between spray dryer equipment configuration and particle design that is often overlooked in the literature due to the widespread use of small-scale fixed geometry equipment. The main equipment configurations which affect the quality attributes of spray 
dried product are process layout (co-current, counter current), drying chamber dimensions, choice of closed/open cycle mode, atomisation device, and powder collection system.

\subsubsection{Process layout}

Pharmaceutical spray dryers mostly use a co-current process layout i.e. the gas flow and droplet atomisation are in the same direction (Figure 3), because of the milder temperature conditions experienced in this process layout and the thermal sensitivity of pharmaceutical materials [65].

\subsubsection{Drying chamber dimensions}

Chamber dimensions is an important process configuration which largely dictates the aerodynamics of air/gas flow and eventually affects droplet residence time. An average value for residence time (disregarding the aerodynamics and droplet size distribution) is roughly estimated through dividing the chamber volume $V$ by the inlet gas volumetric flow rate $U$ [87]. Hence, a chamber with a bigger volume potentially leads to longer residence time and achieves a lower moisture content. However, this may also lead to higher extent of thermal degradation. In pharmaceutical spray drying, the level of moisture or residual solvent content of a powder is sometimes difficult to control without the use of secondary drying equipment such as externally mounted fluid beds [97] or secondary drying chambers [98].

\subsubsection{Choice of closed/open cycle mode}

Open or closed cycle configurations of a spray dryer could affect particle properties e.g. residual solvent content (moisture) and porosity $[12,64]$. In the closed cycle mode, a higher amount of solvent vapour exists in the recycled drying gas $[6,64]$ which causes the solvent evaporation rate to drop, ultimately leading to higher residual solvent content. The latter could in turn decrease particle $T_{g}[64]$ or cause incomplete pore formation and lower particle 
porosity [12]. To avoid these pitfalls, a small amount of fresh drying gas could be channelled into the closed cycle loop to reduce the amount of solvent vapour and improve evaporation efficiency [6].

\subsubsection{Atomisation device}

Two fluid atomisers are mostly used to produce particles which are in the fine range e.g. 1-30 $\mu \mathrm{m}$. These are the standard atomisers for preparing DPI formulations requiring small particle size $\left(d_{a}\right.$ between $\left.2-4 \mu \mathrm{m}\right)$. On the other hand, ultrasonic and pressure atomisers can produce larger droplets which dry into large flowable particles e.g. 100-300 $\mu \mathrm{m}$ useful for oral dosage forms [6]. Schaefer and Lee [99] prepared large flowable particles of protein or disaccharide using an ultrasonic nozzle on a relatively long chamber small-scale spray dryer [100]. Pressure nozzles are mainly used in large scale spray dryers [4]. The use of monodisperse droplet generators (MDGs) was also featured for producing powders with narrow particle size distribution [101]. Pietiläinen [102] reported the use of MDGs in the preparation of particles for precise dosing of APIs in inhalation applications. Nandiyanto and Okuyama [103] described an aerosol-assisted spray method to produce agglomeration-free monodispersed particles.

\subsubsection{Powder collection system}

As mentioned earlier, the choice of cyclone should consider its cut-off value and the desired particle size to maximize collection efficiency. Cyclones could also affect the dried particle morphology by causing weak thin-walled particles to fracture during the powder recovery stage [15]. There are other options for collecting particles such as filters, bag houses, or

electrostatic separators, however, cyclones continue to be the most successful option for pharmaceutical applications. 


\subsection{Feed and process factors}

There are few experimental schemes which link feed and process factors to the final particle structure. The earliest of these reported important theoretical predictions of droplet drying behaviour to help understand morphological transformations in spray dryers [104]. Other schemes focused on the solubility of materials $[105,106]$ and crystallisation within droplets [107]. There are comprehensive schemes such as those of [108] showing the general conditions required for drying different particle morphologies. Furthermore, Nandiyanto and Okuyama [103] reported particle design concepts applicable for inorganic materials based on high temperature processing. Vicente et al. [109] highlighted some critical factors for the formation of particles in spray drying. The different feed and process primary factors relevant to pharmaceuticals were assimilated from the above literature schemes in Table 1 . The impact of these factors on product attributes (e.g. particle size, phase structure etc.) and process smooth operation (e.g. yield, formation of deposits, thermal efficiency) is also highlighted. Table 1 also shows different measurable properties or indicators that could be investigated during spray drying process development.

The primary feed factors reported in Table 1 were those of the solute such as thermal, phase behaviour, physico-chemical, rheological and surface properties, and of the solvent such as its toxicity, flammability, and volatility. The primary process factors were atomisation mechanism, feed rate, gas flow rate and drying temperature.

\subsubsection{Thermal/phase properties on product stability}

The thermal properties of API represent a very important parameter especially in the case of heat-sensitive compounds e.g. biopharmaceuticals. As mentioned earlier in section 2.4, the drying of biopharmaceuticals via spray drying necessitates the use of protective excipients and the optimization of temperature conditions $\left(T_{\text {in }} / T_{\text {out }}\right)$ to prevent denaturation. Thermal 
properties are also important for the preparation of stable solid dispersions (section 2.1). An indication of resultant material's $T_{g}$ helps in selecting a suitable polymer that would drive the combined $T_{g}$ above the storage temperature. Hancock and Zografi [24] provided a 'rule of thumb' to estimate $T_{g}$ from melting point $T_{m}$ of the counter-part crystalline material prior to processing. The basis is an empirical idea that the ratio of $T_{m} / T_{g}$ of most screened pharmaceutical materials is approximately equal to 1.36. More recently, a study [110] confirmed this value through validating it with 71 drug-like compounds.

\subsubsection{Concentration and composition of components on particle size and porosity}

Achieving a specific particle size via controlling the atomised droplet size is vital for both oral and pulmonary dosage forms. The solutes concentration in a given feed solvent is another critical factor to be considered [10]. Generally, particle size increases with increasing the concentration of solids in the drying droplet [81] as could also be inferred from Equation 2 (section 3.2). Contrarily, some researchers reported a limited influence for concentration and dependence of particle size on atomisation [109]. Powders for oral solid dosage forms generally require a particle size above $100 \mu \mathrm{m}$ to provide good flowability [111]. Contrarily, powders for inhalation require small particle size $(d$ of $\approx 5 \mu \mathrm{m})$ and optimised aerodynamic properties $\left(d_{a}\right.$ of 2-4 $\left.\mu \mathrm{m}\right)$ (Section 2.2). Particle $d_{a}$ is a function of its geometric size $d_{g}$ (interchangeable with $\left.d_{p}\right)$ where $d_{a}=d_{g} \sqrt{ }\left(\rho_{e} / \rho_{w} \chi\right)$. Where $\rho_{e}$ represents the envelope density of the particle (interchangeable with $\rho_{p}$ ), $\rho_{w}$ the density of water and $\chi$ the shape factor for non-spherical particles ( $\chi$ is 1 for spherical particles) [112]. The creation of porous or hollow particles lowers $\rho_{e}$ and consequently $d_{a}$, thus facilitating the travel of particles to the alveolar region of the lungs. Different methods were reported in the literature for the creation of porous particles via spray drying [113]. The basic principle in most of these is the evaporation of a volatile material from a drying particle leaving pores behind. Volatile materials such as ammonium carbonate/bicarbonate [5, 12, 98] and fluorocarbons [3] were 
used previously. On the other hand, the development of porous low density powders constitutes a challenge during filling into individual dose units and upon re-dispersion of the powder. Therefore, trileucine or leucine are used in a number of DPI formulations due to their role in further enhancing the dispersion properties and reducing agglomeration [51, 69, $114,115]$

\subsubsection{Choice of solvent and physico-chemical properties on particle morphology}

As mentioned earlier, the choice of solvent or solvent mixtures can affect particle formation. Depending on its evaporative capacity i.e. latent heat of vaporization $\lambda$, a solvent could influence the movement of solute molecules towards the drying droplet centre. According to Péclet, this results in either $\kappa>8 D$ and shell formation if the solvent evaporates quickly or $\kappa$ $<8 D$ and dense particle formation if the surface accumulation is slower than solute diffusion towards the droplet centre. More research is required into the effect of solvent or mixture of solvents on particle morphology through the effect on solubility of components in multicomponent mixtures [116]. For multicomponent solutions, component segregation inside the drying droplet and eventually in the dried particle may also be observed. This potentially occurs if the components have significantly different values for diffusion coefficient and solubility [117]. On the other hand, for solid nano-/microparticles initially dispersed in the evaporating droplet, inter-particle forces may restrict diffusion, therefore the potential for such interactions on the final particle structure may be considered.

Morphology, as well as surface habit, are important for good flowability of powders e.g. spherical particles have better flowability than needle shaped particles. Surface roughness attained from the habit of primary particles (or crystallites) helps the inter-locking of particles [118] during the compression of tablets and also necessary for the design of carrier particles for inhalation. The addition of certain excipients to the feed e.g. sucrose or lactose was reported to reduce the formation of dents on the surface of particles [119]. Surface activity of 
some proteins drives them towards the air-liquid interface of droplets during drying and could lead to their denaturation [120]. However, the addition of surfactants e.g. polysorbate 80 or sodium dodecyl sulfate hindered protein (bovine serum albumin) adsorption at the water/airinterface during drying and reduced protein inactivation or aggregation [121]. Finally, one of the key challenges of the controlled release systems produced via spray drying is managing the thickness of the film formed on the surface of particles to allow controlled drug diffusion and avoid burst drug release.

\subsubsection{Gas and feed flow rates on particle size and moisture content}

Increasing gas flow rate, $U$, changes the aerodynamics within the dryer which in turn influence particle size and moisture content if the residence time becomes longer or causes wall deposits if turbulent flows are created.

Increasing the feed flow rate, $F$, decreases $T_{\text {out }}$ and vice versa, which in turn will affect the moisture content, $T_{g}$ and yield as will be explained next. Increasing $F$ also increases the droplet size and eventually the particle size (Equation 2).

\subsubsection{Temperature conditions on process yield}

The relationship between temperature conditions $\left(T_{\text {in }} / T_{\text {out }}\right)$ and process yield was explored by Imtiaz-Ul-Islam and Langrish [122] through a concept termed the 'stickiness barrier'. They found that for sugar rich materials which usually turn amorphous upon rapid drying, yield increases with increasing $T_{\text {in }}$ (consequently $T_{o u t}$ ). This is because the increase in temperature leads to a decrease in moisture content and therefore higher materials' $T_{g}$. Thus, the materials in the particle would be less susceptible to stickiness due to higher chance of staying in the glassy highly viscous state as explained previously (section 3.4). However, yield would decrease as $T_{\text {in }}$ increases further, due to no more reduction in the moisture content (i.e. $T_{g}$ is almost constant at this stage). This phase is called the 'stickiness barrier' period which is characterised by very low yield due to particle temperature close to or 
exceeding $T_{g}$. Further increase in the temperature, however, will cause recrystallization of the amorphous form and yet increases yield again. Note that many amorphous materials may not recrystallize upon the higher temperature and undergo decomposition instead.

\section{Scale-up approaches}

In most situations, the biggest challenge in scale-up is delivering the same particle size and structure, and consequently properties and performance, on the production scale as those designed and optimised on the small scale. In dryers, this is more challenging than some other unit operations because of the significant interaction between process conditions and product structure and properties [123]. The complexities, and number, of the numerous interacting mechanisms happening across all length scales in a spray dryer make classical process scale-up approaches, using dimensional analysis, of limited use. Similarity cannot be maintained for all the important mechanisms and associated dimensionless groups even if geometric similarity was preserved (which in reality it never is).

One of the objectives in dryer scale-up is recognising the scale-independent process parameters necessary to achieve the target particle properties [123]. Ideally, one would match the following key parameters across scales 1) feed properties and feed moisture content; 2) atomised droplet size distribution; 3) the droplet drying history and history distribution; 4) the desired particle/droplet collision history to form agglomerates and 5) avoid wall contacts and build-up at all scales. Attempts have been made to do this for some systems [124], and matching drying history might be possible if the extra drying time at full scale is not having a significant effect on drying. However, in most cases it is not possible, and differences are seen across scales in particle size, morphology, and product residual solvent/moisture content. The differences are attributable to scale-driven limitations and practical differences in tower design at different scales. 
On the small scale, relatively dilute feeds tend to be used to reduce the higher pressure drops which occur in scaled down feed lines and limitations in small scale pump capability. The particle size is also necessarily small on the small scale due to the very low residence times available for drying. Lab dryers in particular have very low residence times, $<1 \mathrm{~s}$ [125], and even pilot scale towers have shorter residence times, for example, particle residence times of $20 \mathrm{~s}$ on the pilot scale compared with $40 \mathrm{~s}$ on the production scale [124]. Small scale spray dryers are typically equipped with two-fluid nozzles producing small particles whereas large scale spray dryers use pressure nozzles producing larger particles (see section 4.1) [64]. It is possible, from a practical point of view, to adjust the feed composition (e.g. initial concentration) to match the residence/drying time of the scaled-up process. However, such changes need to be approached carefully to avoid variation in product quality or extra regulatory burden.

It is also important to realise that heat loss from the dryer walls and yield vary between the scales [97]. In particular, yields on the small-scale spray dryer are limited to $60-70 \%$ due to a large fraction of fine particles lost in the filters and formation of wall deposits (see section 3.4). The latter happens due to incomplete drying and poor thermal efficiency on the smallscale and can significantly change the product properties. Whereas on the production scale chamber deposits must be minimized by optimising the operation to achieve hygienic (or even aseptic) conditions (the better thermal efficiency intrinsically helps) [97]. In the next sections, the alternative main approaches for scale-up of pharmaceutical spray drying are summarised.

\subsection{Basis for scale-up approach}

This is one of the traditional approaches for scale-up which mostly relies on the experience and 'know-how' of the spray dryer designer [97]. Scale-up via this approach requires 
sufficient prior knowledge on heat-mass transfer, the effect of humidity, individual's practical expertise (process and component scale-up) and some information on the properties of product from pilot-scale experiments. The basis for this approach is the use of 'well-proven' techniques from practical experience rather than engaging in a theoretical intensive exercise.

Basis for scale-up links the process factors to product properties via the mechanisms occurring within the tower. These could be fixed factors such as dryer geometry and feed composition or variables such as operating conditions, e.g. atomiser pressure and inlet temperature, linked to the possible outputs from the process i.e. desired properties of the product [126]. The use of the notion 'fixed factors' here refers to the fact that changes to geometry of the process or feed composition are not preferable options given the consequences of such interventions on other business or regulatory aspects of the product. For example, changes to process components may necessitate further design and process engineering with all the associated costs. Similarly, changes to the feed composition, while sometimes inevitable, are not recommended as first option due to potential requirement of new costly bioequivalence studies to establish similarity [127]. After identification of the fixed and variable factors of scale-up, different numerical or empirical models and experimental tools are used to investigate the effect of each critical factor on the process outputs. The outcome of this procedure is identification of the key process parameters that may result in a product with similar attributes over the different scales.

\subsection{Thermodynamic space approach}

Scale up via this approach commences with extensive experimental work to establish a stable lab-scale process. This is necessary to derive the optimal product and process parameters such as temperature, $T_{\text {in }}$ or $T_{\text {out }}$, condenser temperature, $T_{\text {cond }}$, as well as drying gas rate, $U$, and feed flow rate, $F$. Energy and mass balance calculations and liquid vapour equilibrium 
models are then used to derive parameters such as $\mathrm{Cr}_{\text {out }}$ which is the concentration of solvent in the gas phase relative to its concentration at saturation. The value of $\mathrm{Cr}_{\text {out }}$ obtained from small scale measurements relates to the residual solvent within the sample and consequently influences materials' $T_{g}$ [64]. One of the criteria in this scale-up methodology is to maintain the same value of $C r_{\text {out }}$ at the large scale via modifying $F$ and $T_{\text {out }}$. The next step is estimation of the droplet size obtained from the atomisation process mainly via empirical droplet size correlations. Those correlations are nozzle and product dependent and may not describe the complex fluid dynamics of droplet formation. This is followed by experimental measurements of particle bulk density and the use of a simple mass balance calculation to estimate the dried particle size $[64,128]$.

\subsection{Iterative mathematical-statistical models}

The use of mathematical and statistical models for process optimization and scale-up have risen since design of experiments (DOE) is playing a bigger role in quality by design (QbD) pharmaceutical development. The main purpose of these models is to generate a design space based on experimental observations from a limited number of experiments [4]. This could be cost-effective considering the nature of the scale-up task which requires extensive experimental effort. Several studies have considered the effect of process parameters on critical quality attributes (CQAs) or established the design space for a lab-scale spray drying process [129-131]. However, the design space created on the small scale may not apply at larger scales due to the differences mentioned earlier e.g. temperature, initial drop size, residence time etc. Therefore, a common practice is to re-validate the design space upon scale-up. It is also important to mention that DOE studies performed on the small-scale help in defining the critical process parameters (CPPs) which could then be considered during the scale-up operation. Additionally, this is a growing area of research where incremental advances are made towards more robust and scalable models. 


\subsection{Fundamental models}

The use of computational fluid dynamics (CFD) to solve fluid motion equations enabled the prediction of gas flow aerodynamics, droplet-gas contact and droplet trajectories during spray drying. This has made CFD a very useful tool for the scale-up of spray drying as the theoretical information obtained on fluid dynamics facilitates the decision to build commercial scale plant [7]. Furthermore, optimization of spray drying yield and understanding the deposition within spray dryers has also been attempted using CFD when combined with experimentally obtained droplet drying models of the large scale process [88]. However, there are number of challenges with this approach, such as the need for computationally expensive unsteady models of the turbulent flow and the challenge in obtaining good quality drying data [7]. It has also been highlighted that the models are only based on a limited number of representative drops [87]. In reality, thousands of droplets are produced in a spray dryer with complex interactions such as coalescence and agglomeration unaccounted for using current models. In addition, validation runs are required at least on a pilot scale plant to ensure the robustness of the simulation data $[7,132]$. Due to the complexities of the CFD models, and the experts required to run them, simpler rate base models can also be used e.g. $[133,134]$ and whilst they may be more limited in geometry related aspects of optimisation, can still be a useful tool for scale-up [7].

\subsection{Hybrid approach}

This is in fact a combination of some of the above approaches utilising the best practices from each. It starts with initial experimental screening of the best formulations to establish feed composition, solvent type etc. and defining process constraints e.g. maximum and minimum operational process parameters necessary for smooth process operation. This is followed by creating a thermodynamics map for the effect of feed rate and outlet temperature 
on maximizing drying efficiency on small scale. The next stage is to use CFD to predict droplet drying kinetics followed by iterating the CFD model via experimental phase doppler measurements of the atomised droplet size. Finally, a verification run is carried out on the pilot scale to validate the CFD results and establish scale-up procedure [132].

\section{Conclusions}

Spray drying has been used to design many particle delivery systems. It represents an effective option for the solubilisation of even practically insoluble APIs via solid dispersions especially for oral drug delivery. Spray drying is also a major processing technique in the pulmonary drug delivery area to constructively design particles with the required size, density and surface properties. The technique has also been used to microencapsulate APIs and achieve controlled release kinetics for oral, pulmonary and parenteral delivery. The overwhelming literature evidence supports the use of spray drying for drying heat-sensitive compounds e.g. biopharmaceuticals. However, the conditions of the process and feed parameters have to be controlled to avoid denaturation.

The feed stage of the process significantly impacts the final particle properties and the product recovery from the process. The ability to control particle size and density for different applications e.g. small size and low density for inhalation or large size and high density for oral dosage forms via modifying the atomisation device or drying conditions is

probably the techniques' biggest advantage. There has been a number of schemes linking process parameters to particle attributes such as size and morphology to eventually enable product specification control. However, this is continuing to pose a challenge given the complexity and interactions within the process. The formation of crystalline or amorphous solids during the drying process is a very difficult product attribute to ascertain without experimental effort. Dryer scale-up is also very challenging given the samples produced on 
the small scale may not represent the large-scale product attributes due to variations in the process conditions.

\section{Expert opinion}

The spray drying process is well established in many industrial sectors; however, it is only in recent years that the benefits of the process are being seen and realised by the pharmaceutical sector, as the needs of new therapeutics drive product developers beyond existing, established, manufacturing routes. Many of these benefits come from the ability to directly formulate and design particles of the desired functionality. Much of the research reported are formulation studies which explore the link between formulation and functionality often using lab-scale trial and error approaches. These studies are typically limited in their breadth of application beyond the investigated formulation space.

The complexities of the spray drying process and the phenomena occurring at both particle and process scales make both studying and modelling these systems very challenging, however, advances in both experimental and modelling approaches have been made. These include conceptual models based on the Péclet number [113] and more complex models [106] that have helped us understand the mechanisms and predict behaviour. On a single particle level the ability to predict the particle 'structure' for a given formulation, particle size, solvent level and drying condition remains a long standing need and challenge.

The link between material physical properties and particle structure remains an open area for active research. An increased attention to physical property specification, testing and control is a natural evolution of current pharmaceutical trends. Recent innovations in material characterisation and data analysis approaches have shown that not only API size but shape can play an important role in the manufacturability of pharmaceutical products [135]. Regulatory authorities are well aware that API physical properties can have influence beyond 
dissolution rates governed by surface area. Examples of other influenced properties recognized by the regulator include product processability, content uniformity and product appearance (See ICH Q6A Specifications Decision Tree 3) [136]. Consequently, it is quite probable that API physical specifications will become more encompassing and exacting in the future. Improved control over these properties, potentially offered by advanced manufacturing technologies, is welcomed.

Perhaps the biggest barriers to the spray dried product translation remains one of scale-up and scale-down i.e. the ability to make particles in the large scale that are of the same properties as that made on the small scale. Developments in CFD are enabling the prediction of differences in drying behaviour, though, the challenge remains that of the short residence time on the small scale. The ability to robustly and simply measure drying rates is also a key need that would enable CFD and modelling approaches to be more widely used in the product development cycle. Furthermore, in early phase drug development, material is not available for scale-up and the physical limitations of scale-down experiments mean it can be very hard to generate samples representative of material that could be obtained long-term at larger scale - a particular limitation when you consider that samples may be required that are manufactured to Good Manufacturing Practice (GMP) standards. Improved understanding and technological developments of small scale manufacture combined with companies and labs capable of operating it under suitable conditions is critical to driving the use of spray drying and maximising the value it can bring.

The adoption of spray drying technology for creating drug delivery applications is especially evident in the areas of solid dispersions formulation for solubility enhancement and for the formulation of aerosolised particles for DPIs. In the future, the introduction of new or improved spray drying technologies could help accelerate the design and robust manufacture of precision medicines, bio-derived APIs and targeted drug delivery systems. This is 
strengthened by the current record of spray drying as a continuous and regulatory approved process.

Furthermore, it is expected that more modelling techniques will be used to design spray drying processes/systems tailored for the pharmaceutical sector rather than reapplication of $20^{\text {th }}$ century technology. Product design approaches encompassing model-based 'digital design' methods and associated experimental techniques will hopefully come together for an integrated work modality. There is also an increased interest in a continuous verification model that would essentially look to link process parameters to product physical properties via PAT tools and ultimately predict product performance of spray dried products.

\section{Bibliography}

[1] Plumb K. Continuous Processing in the Pharmaceutical Industry Changing the Mind Set. Chem Eng Res Des 2005; 83: 730-738.

[2] Lee SL, O'Connor TF, Yang X, et al. Modernizing Pharmaceutical Manufacturing: from Batch to Continuous Production. J Pharm Innov 2015; 10: 191-199.

[3] Dellamary LA, Tarara TE, Smith DJ, et al. Hollow Porous Particles in Metered Dose Inhalers. 2000; 17: 168-174.

- This paper discusses the creation of porous particles for inhalation.

[4] Costa E, Fiilipe N, Andrade G, et al. Scale-up \& QBD Approaches for spray-dried Inhalation Formulations. www.ondrugdelivery.com, 2014, pp. 3-8.

[5] Al-Khattawi A, Koner J, Rue P, et al. A pragmatic approach for engineering porous mannitol and mechanistic evaluation of particle performance. Eur J Pharm Biopharm 2015; 94: 1-10.

- This paper discusses the creation of porous particles for oral drug delivery.

[6] Masters K. Spray drying handbook. 5th ed. Harlow: Longman Scientific \& Technical, 1991.

- This book is very useful for students and industry people interested in learning about spray drying. 
[7] Oakley DE. Scale-Up of Spray Dryers With the Aid of Computational Fluid Dynamics. Dry Technol 1994; 12: 217-233.

- This paper discusses the scale-up of spray drying with the aid of CFD.

[8] Okuyama K, Abdullah M, Lenggoro IW, et al. Preparation of functional nanostructured particles by spray drying. Adv Powder Technol 2006; 17: 587-611.

[9] Mezhericher M, Levy a., Borde I. Theoretical Models of Single Droplet Drying Kinetics: A Review. Dry Technol 2010; 28: 278-293.

- An important review on the theoretical models for single droplet drying.

[10] Mosén K, Bäckström K, Thalberg K, et al. Particle Formation and Capture During Spray Drying of Inhalable Particles. Pharm Dev Technol 2005; 9: 409-417.

[11] Al-Obaidi H, Brocchini S, Buckton G. Anomalous properties of spray dried solid dispersions. J Pharm Sci 2009; 98: 4724-37.

[12] Nolan LM, Tajber L, McDonald BF, et al. Excipient-free nanoporous microparticles of budesonide for pulmonary delivery. Eur J Pharm Sci 2009; 37: 593-602.

[13] Vehring R, Foss WR, Lechuga-Ballesteros D. Particle formation in spray drying. $J$ Aerosol Sci 2007; 38: 728-746.

- This paper discusses particle formation and some of the equations governing the drying stage.

[14] Schiffter H, Lee G. Single-droplet evaporation kinetics and particle formation in an acoustic levitator. Part 2: drying kinetics and particle formation from microdroplets of aqueous mannitol, trehalose, or catalase. J Pharm Sci 2007; 96: 2284-95.

[15] Foster T, Leatherman M. Powder characteristics of proteins spray-dried from different spray-dryers. Drug Dev Ind Pharm 1995; 21: 1705-1723.

[16] PRNewswire. Pharmaceutical Spray Drying Market, 20142024http://www.reportlinker.com/p02185204/Pharmaceutical-Spray-Drying-Market2014-2024.html (2014).

[17] Rojas J, Kumar V. Effect of polymorphic form on the functional properties of cellulose: A comparative study. Carbohydr Polym 2012; 87: 2223-2230.

[18] EMEA CHMP. INTELENCE:

Etravirinehttp://www.ema.europa.eu/docs/en_GB/document_library/EPAR__Public_assessment_report/human/000900/WC500034183.pdf (2008).

[19] EMEA CHMP. Assessment Report Kalydeco. 2012.

[20] Kwong AD, Kauffman RS, Hurter P, et al. Discovery and development of telaprevir: an NS3-4A protease inhibitor for treating genotype 1 chronic hepatitis $\mathrm{C}$ virus. Nat Biotechnol 2011; 29: 993-1003.

[21] Neumiller JJ, Campbell R keith. Technosphere Insulin: An Inhaled Prandial Insulin Product. Biodrugs 2010; 24: 165-172. 
[22] VanDevanter DR, Geller DE. Tobramycin administered by the TOBI ${ }^{\circledR}$ Podhaler ${ }^{\circledR}$ for persons with cystic fibrosis: a review. Med Devices Evid Res 2011; 4: 179-188.

[23] FDA. FDA approves Raplixa to help control bleeding during surgery: First spray-dried fibrin sealant approved by the agency. FDA News

Releasehttp:/www.fda.gov/newsevents/newsroom/pressannouncements/ucm445247.ht m (2015, accessed 30 November 2016).

[24] Hancock B, Zografi G. Characteristics and significance of the amorphous state in pharmaceutical systems. J Pharm Sci 1997; 86: 1-12.

- This paper discusses the amorphous state in pharmaceutical systems in detail.

[25] Paudel A, Worku ZA, Meeus J, et al. Manufacturing of solid dispersions of poorly water soluble drugs by spray drying: formulation and process considerations. Int $J$ Pharm 2013; 453: 253-84.

- This paper provides an in-depth account of solid dispersions formulation development using spray drying.

[26] Greenhalgh DJ, Williams AC, Timmins P, et al. Solubility parameters as predictors of miscibility in solid dispersions. J Pharm Sci 1999; 88: 1182-1190.

[27] Widanapathirana L, Tale S, Reineke TM. Dissolution and Solubility Enhancement of the Highly Lipophilic Drug Phenytoin via Interaction with Poly(Nisopropylacrylamide-co-vinylpyrrolidone) Excipients. Mol Pharm 2015; 12: 2537 2543.

[28] Teixeira CCC, Mendonca LM, Bergamaschi MM, et al. Microparticles Containing Curcumin Solid Dispersion: Stability, Bioavailability and Anti-Inflammatory Activity. AAPS PharmSciTech 2016; 17: 252-261.

[29] Mihajlovic T, Kachrimanis K, Graovac A, et al. Improvement of aripiprazole solubility by complexation with (2-hydroxy)propyl- $\beta$-cyclodextrin using spray drying technique. AAPS PharmSciTech 2012; 13: 623-31.

[30] Sonje VM, Kumar L, Puri V, et al. Effect of counterions on the properties of amorphous atorvastatin salts. Eur J Pharm Sci 2011; 44: 462-470.

[31] Serajuddin ATM. Salt formation to improve drug solubility. Adv Drug Deliv Rev 2007; 59: 603-616.

[32] Kim DW, Kang JH, Oh DH, et al. Development of novel flurbiprofen-loaded solid self-microemulsifying drug delivery system using gelatin as solid carrier. $J$ Microencapsul 2012; 29: 323-330.

[33] Kamel AO, Mahmoud AA. Enhancement of human oral bioavailability and in vitro antitumor activity of rosuvastatin via spray dried self-nanoemulsifying drug delivery system. J Biomed Nanotechnol 2013; 9: 26-39.

[34] Ha ES, Ok J, Noh J, et al. Fabrication and evaluation of celecoxib microparticle surface modified by hydrophilic cellulose and surfactant. Int J Biol Macromol 2015; 72: $1473-1478$. 
[35] Martins RM, Machado MO, Pereira S V., et al. Engineering Active Pharmaceutical Ingredients by Spray Drying: Effects on Physical Properties and In Vitro Dissolution. Dry Technol 2012; 30: 905-913.

[36] Patil SP, Modi SR, Bansal AK. Generation of 1:1 Carbamazepine:Nicotinamide cocrystals by spray drying. Eur J Pharm Sci 2014; 62: 251-257.

[37] Seville PC, Li H, Learoyd TP. Spray-Dried Powders for Pulmonary Drug Delivery. Crit Rev Ther Drug Carr Syst 2007; 24: 307-360.

[38] Tsapis N, Bennett D, Jackson B, et al. Trojan particles: large porous carriers of nanoparticles for drug delivery. Proc Natl Acad Sci U S A 2002; 99: 12001-5.

[39] Littringer EM, Mescher A, Schroettner H, et al. Spray dried mannitol carrier particles with tailored surface properties - The influence of carrier surface roughness and shape. Eur J Pharm Biopharm 2012; 82: 194-204.

[40] El-Sherbiny IM, Smyth HDC. Biodegradable nano-micro carrier systems for sustained pulmonary drug delivery: (I) Self-assembled nanoparticles encapsulated in respirable/swellable semi-IPN microspheres I. Int J Pharm 2010; 395: 132-141.

[41] Edwards DA, Hanes J, Caponetti G, et al. Large Porous Particles for Pulmonary Drug Delivery. Science (80- ) 1997; 276: 1868-1871.

[42] Vanbever R, Mintzes JD, Wang J, et al. Formulation and Physical Characterization of Large Porous Particles for Inhalation. Pharm Res 1999; 16: 1735-1742.

[43] Edwards DA. Delivery of biological agents by aerosols. AIChE J 2002; 48: 2-6.

[44] Straub J a, Chickering DE, Church CC, et al. Porous PLGA microparticles: AI-700, an intravenously administered ultrasound contrast agent for use in echocardiography. $J$ Control Release 2005; 108: 21-32.

[45] Re M. Microencapsulation by Spray Drying. Dry Technol 1998; 16: 1195-1236.

- This paper discusses microencapsulation using spray drying in a number of industries.

[46] Gavini E, Sanna V, Juliano C, et al. Compressed biodegradable matrices of spray-dried PLGA microspheres for the modified release of ketoprofen. J Microencapsul 2003; 20: 193-201.

[47] Sun Y, Cui F, Shi K, et al. The Effect of Chitosan Molecular Weight on the Characteristics of Spray-Dried Methotrexate-Loaded Chitosan Microspheres for Nasal Administration. Drug Dev Ind Pharm 2009; 35: 379-386.

[48] Nettey H, Haswani D, Oettinger CW, et al. Formulation and testing of vancomycin loaded albumin microspheres prepared by spray-drying. J Microencapsul 2006; 23: 632-642.

[49] Edwards DA, Hanes J, Caponetti G, et al. Large Porous Particles for Pulmonary Drug Delivery. Science (80- ) 1997; 276: 1868-1871.

[50] Kusonwiriyawong C, Atuah K, Alpar OH, et al. Cationic stearylamine-containing biodegradable microparticles for DNA delivery. J Microencapsul 2004; 21: 25-36. 
[51] Tawfeek H, Khidr S, Samy E, et al. Poly(glycerol adipate-co- $\omega$-pentadecalactone) Spray-dried microparticles as sustained release carriers for pulmonary delivery. Pharm Res 2011; 28: 2086-2097.

[52] Kilicarslan M, Gumustas M, Yildiz S, et al. Preparation and Characterization of Chitosan-Based Spray-Dried Microparticles for the Delivery of Clindamycin Phosphate to Periodontal Pockets. Curr Drug Deliv 2014; 11: 98-111.

[53] Lee LY, Ranganath SH, Fu Y, et al. Paclitaxel release from micro-porous PLGA disks. Chem Eng Sci 2009; 64: 4341-4349.

[54] Nadal JM, Gomes MLS, Borsato DM, et al. Spray-dried Eudragit ${ }^{\circ}$ L100 microparticles containing ferulic acid: Formulation, in vitro cytoprotection and in vivo anti-platelet effect. Mater Sci Eng C Mater Biol Appl 2016; 64: 318-328.

[55] Guo X, Zhang X, Ye L, et al. Inhalable microspheres embedding chitosan-coated PLGA nanoparticles for 2-methoxyestradiol. J Drug Target 2014; 22: 421-427.

[56] Kohane DS, Anderson DG, Yu C, et al. pH-triggered release of macromolecules from spray-dried polymethacrylate microparticles. Pharm Res 2003; 20: 1533-1538.

[57] Ameri M, Maa Y-F. Spray Drying of Biopharmaceuticals: Stability and Process Considerations. Dry Technol 2006; 24: 763-768.

- The paper discusses some spray drying process considerations for biopharmaceuticals.

[58] Chávez BE, Ledeboer a. M. Drying of Probiotics: Optimization of Formulation and Process to Enhance Storage Survival. Dry Technol 2007; 25: 1193-1201.

[59] Ledet GA, Richard AG, Bostanian LA, et al. Spray-Drying of Biopharmaceuticals. In: Lyophilized Biologics and Vaccines. 2015, pp. 273-297.

[60] Yoshii H, Neoh TL, Furuta T, et al. Encapsulation of Proteins by Spray Drying and Crystal Transformation Method. Dry Technol 2008; 26: 1308-1312.

[61] Haque MA, Adhikari B. Drying and Denaturation of Proteins in Spray Drying Process. In: Handbook of Industrial Drying. 2015, pp. 971-983.

[62] Sosnik A, Seremeta KP. Advantages and challenges of the spray-drying technology for the production of pure drug particles and drug-loaded polymeric carriers. Adv Colloid Interface Sci 2015; 223: 40-54.

[63] Haggag Y a., Faheem AM. Evaluation of nano spray drying as a method for drying and formulation of therapeutic peptides and proteins. Front Pharmacol 2015; 6: 1-5.

[64] Gil M, Vicente J, Gaspar F. Scale-up methodology for pharmaceutical spray drying. Chim oggi/Chemistry Today 2010; 28: 18-22.

[65] Broadhead J, Edmond Rouan SK, Rhodes CT. The spray drying of pharmaceuticals. Drug Dev Ind Pharm 1992; 18: 1169-1206.

- This paper provided a general overview of the technique, properties of spray dried powders and a long list of applications.

[66] Walton DE. the Morphology of Spray-Dried Particles a Qualitative View. Dry Technol 
2000; 18: 1943-1986.

- This is a comprehensive review of the morphology of spray dried particles.

[67] Wan LSC, Heng PWS, Chia CGH. Spray Drying as a Process for Microencapsulation and the Effect of Different Coating Polymers. Drug Dev Ind Pharm 1992; 18: 9971011.

[68] Moran A, Buckton G. Adjusting and understanding the properties and crystallisation behaviour of amorphous trehalose as a function of spray drying feed concentration. Int J Pharm 2007; 343: 12-7.

[69] Sou T, Morton D, Williamson M, et al. Spray-Dried Influenza Antigen with Trehalose and Leucine Produces an Aerosolizable Powder Vaccine Formulation that Induces Strong Systemic and Mucosal Immunity after Pulmonary Administration. $J$ Aerosol Med Pulm Drug Deliv 2015; 28: 361-371.

[70] Andya JD, Maa Y-F, Costantino HR, et al. The Effect of Formulation Excipients on Protein Stability and Aerosol Performance of Spray-Dried Powders of a Recombinant Humanized Anti-IgE Monoclonal Antibody1. Pharm Res 1999; 16: 350-358.

[71] Harvie DJE, Langrish TAG, Fletcher DF. A Computational Fluid Dynamics Study of a Tall-Form Spray Dryer. Food Bioprod Process 2002; 80: 163-175.

[72] Tewa-Tagne P, Degobert G, Briançon S, et al. Spray-drying nanocapsules in presence of colloidal silica as drying auxiliary agent: formulation and process variables optimization using experimental designs. Pharm Res 2007; 24: 650-61.

[73] Choińska A, Mituła P, Śliwka P, et al. Bacteriophage encapsulation: trends and potential applications. Trends Food Sci Technol 2015; 45: 212-221.

[74] Lee SH, Heng D, Ng WK, et al. Nano spray drying: A novel method for preparing protein nanoparticles for protein therapy. Pharm Nanotechnol 2011; 403: 192-200.

[75] Masters K, Vestergaard I. Aseptic and Closed Cycle Spray Drying in Pharmaceutical Biochemicals manufacture. Process Biochem 1975; 10: 1-21.

[76] Rizi K, Green RJ, Donaldson M, et al. Production of pH-responsive microparticles by spray drying: investigation of experimental parameter effects on morphological and release properties. J Pharm Sci 2011; 100: 566-79.

[77] Bain D, Munday D, Smith A. Solvent influence on spray-dried biodegradable microspheres. J Microencapsul 1999; 16: 453-474.

[78] Esposito E, Roncarati R, Cortesi R, et al. Production of Eudragit microparticles by spray-drying technique: influence of experimental parameters on morphological and dimensional characteristics. Pharm Dev Technol 2000; 5: 267-78.

[79] Wu JX, Yang M, van den Berg F, et al. Influence of solvent evaporation rate and formulation factors on solid dispersion physical stability. Eur J Pharm Sci 2011; 44: $610-620$.

[80] Lefebvre AH. Atomization and Sprays. Boca Raton: CRC Press, 1989. 
•• This is an important book on atomisation and spray formation mechanisms.

[81] Thybo P, Hovgaard L, Andersen SK, et al. Droplet size measurements for spray dryer scale-up. Pharm Dev Technol 2008; 13: 93-104.

[82] Iskandar F, Gradon L, Okuyama K. Control of the morphology of nanostructured particles prepared by the spray drying of a nanoparticle sol. J Colloid Interface Sci 2003; 265: 296-303.

[83] El-Sayed TM, Wallack DA, King CJ. Changes in particle morphology during drying of drops of carbohydrate solutions and food liquids. 1. Effect of composition and drying conditions. Ind Eng Chem Res 1990; 29: 2346-2354.

[84] Mahlin D, Bergström C a S. Early drug development predictions of glass-forming ability and physical stability of drugs. Eur J Pharm Sci 2013; 49: 323-32.

[85] Nešić S, Vodnik J. Kinetics of droplet evaporation. Chem Eng Sci 1991; 46: 527-537.

[86] Handscomb CS, Kraft M, Bayly AE. A new model for the drying of droplets containing suspended solids. Chem Eng Sci 2009; 64: 628-637.

[87] Fletcher DF, Guo B, Harvie DJE, et al. What is important in the simulation of spray dryer performance and how do current CFD models perform? Appl Math Model 2006; 30: $1281-1292$.

[88] Ullum T, Sloth J, Brask a., et al. Predicting Spray Dryer Deposits by CFD and an Empirical Drying Model. Dry Technol 2010; 28: 723-729.

[89] Ozmen L, Langrish TAG. Comparison of Glass Transition Temperature and Sticky Point Temperature for Skim Milk Powder. Drying Technology 2002; 20: 1177-1192.

- This paper discusses the concept of sticky point temperature in relation to powder deposition in dryers.

[90] Palzer S. Agglomeration of Dehydrated Consumer Foods. In: Salman AD, Hounslow MJ, Seville JPK (eds) Granulation. Elsevier B.V., 2007, pp. 591-671.

[91] Bhandari B., Howes T. Implication of glass transition for the drying and stability of dried foods. J Food Eng 1999; 40: 71-79.

[92] Graham LJ, Taillon R, Mullin J, et al. Pharmaceutical process/equipment design methodology case study: Cyclone design to optimize spray-dried-particle collection efficiency. Comput Chem Eng 2010; 34: 1041-1048.

[93] Cortes C, Gil A. Modeling the gas and particle flow inside cyclone separators. Prog Energy Combust Sci 2007; 33: 409-452.

[94] Peng W, Hoffmann AC, Dries HWA, et al. Experimental study of the vortex end in centrifugal separators: The nature of the vortex end. Chem Eng Sci 2005; 60: 69196928.

[95] Maa YF, Nguyen PA, Sit K, et al. Spray-drying performance of a bench-top spray dryer for protein aerosol powder preparation. Biotechnol Bioeng 1998; 60: 301-309.

[96] Maury M, Murphy K, Kumar S, et al. Effects of process variables on the powder yield 
of spray-dried trehalose on a laboratory spray-dryer. Eur J Pharm Biopharm 2005; 59: 565-573.

[97] Masters K. Scale-Up of Spray Dryers. Dry Technol 1994; 12: 235-257.

[98] Straub J a., Chickering DE, Lovely JC, et al. Intravenous Hydrophobic Drug Delivery: A Porous Particle Formulation of Paclitaxel (AI-850). Pharm Res 2005; 22: 347-355.

[99] Schaefer J, Lee G. Post-chamber inactivation of catalase powder during spray drying in bench-top machines. Powder Technol 2015; 277: 231-236.

[100] Schaefer J, Lee G. Making large, flowable particles of protein or disaccharide in a mini-scale spray dryer. Pharm Dev Technol 2015; 1-9.

[101] Rogers S, Wu WD, Lin SXQ, et al. Particle shrinkage and morphology of milk powder made with a monodisperse spray dryer. Biochem Eng J 2012; 62: 92-100.

[102] Pietiläinen J. Spray Drying Particles from Ethanol-Water Mixtures Intended for Inhalation. 2013.

[103] Nandiyanto ABD, Okuyama K. Progress in developing spray-drying methods for the production of controlled morphology particles: From the nanometer to submicrometer size ranges. Adv Powder Technol 2011; 22: 1-19.

[104] Charlesworth DH, W. R. Marshall JR. Evaporation from Drops Containing Dissolved Solids. AIChE J 1960; 6: 9-23.

[105] Handscomb CS, Kraft M, Bayly AE. A new model for the drying of droplets containing suspended solids after shell formation. Chem Eng Sci 2009; 64: 228-246.

[106] Mezhericher M, Levy A, Borde I. Theoretical Drying Model of Single Droplets Containing Insoluble or Dissolved Solids. Dry Technol 2007; 25: 1025-1032.

- This paper discusses a theoretical drying model of single droplets.

[107] Leong K. Morphological control of particles generated from the evaporation of solution droplets: Theoretical considerations. J Aerosol Sci 1987; 18: 511-524.

[108] Walton D, Mumford C. The morphology of spray-dried particles: the effect of process variables upon the morphology of spray-dried particles. Chem Eng Res Des 1999; 77: 442-460.

[109] Vicente J, Pinto J, Menezes J, et al. Fundamental analysis of particle formation in spray drying. Powder Technol 2013; 247: 1-7.

[110] Alzghoul A, Alhalaweh A, Mahlin D, et al. Experimental and computational prediction of glass transition temperature of drugs. J Chem Inf Model 2014; 54: 3396-403.

[111] Liu LX, Marziano I, Bentham AC, et al. Effect of particle properties on the flowability of ibuprofen powders. Int J Pharm 2008; 362: 109-117.

[112] Hickey AJ. Pharmaceutical Inhalation Aerosol Technology. New York: Marcel Dekker, 2004.

[113] Vehring R. Pharmaceutical particle engineering via spray drying. Pharm Res 2008; 25: 
999-1022.

-• This is one of the very important reviews on the topic of particle engineering using spray drying.

[114] Lechuga-Ballesteros D. Trileucine improves aerosol performance and stability of spray-dried powders for inhalation. J Pharm Sci 2008; 97: 287-302.

[115] Najafabadi AR, Gilani K, Barghi M, et al. The effect of vehicle on physical properties and aerosolisation behaviour of disodium cromoglycate microparticles spray dried alone or with 1-leucine. Int J Pharm 2004; 285: 97-108.

[116] Leong KH. Morphology of aerosol particles generated from the evaporation of solution drops. J Aerosol Sci 1981; 12: 417-435.

[117] Gac JM, Gradoń L. A distributed parameter model for the spray drying of multicomponent droplets with a crust formation. Adv Powder Technol 2013; 24 : 324 330.

[118] Al-Khattawi A, Alyami H, Townsend B, et al. Evidence-based nanoscopic and molecular framework for excipient functionality in compressed orally disintegrating tablets. PLoS One 2014; 9: e101369.

[119] Lay Ma U V., Ziegler GR, Floros JD. Effect of sucrose on physical properties of spray-dried whole milk powder. J Food Sci 2008; 73: 431-438.

[120] Magdassi A, Kamyshny A. Surface activity and functional properties of proteins. In: S M (ed) Surface Activity of Proteins. New York: Marcel Dekker, 1996, pp. 1-38.

[121] Adler M, Unger M, Lee G. Surface composition of spray-dried particles of bovine serum albumin/trehalose/surfactant. Pharm Res 2000; 17: 863-870.

[122] Imtiaz-Ul-Islam M, Langrish T a G. Comparing the crystallization of sucrose and lactose in spray dryers. Food Bioprod Process 2009; 87: 87-95.

[123] Genskow LR. Dryer Scale-Up Methodology for the Process Industries. Dry Technol 1994; 12: 47-58.

[124] Thybo P, Hovgaard L, Lindeløv JS, et al. Scaling up the spray drying process from pilot to production scale using an atomized droplet size criterion. Pharm Res 2008; 25 : $1610-20$.

[125] Kemp IC, Hartwig T, Herdman R, et al. Spray drying with a two-fluid nozzle to produce fine particles: Atomization, scale-up, and modeling. Dry Technol 2016; 34 : $1243-1252$.

[126] Chen XD. Heat-Mass Transfer and Structure Formation During Drying of Single Food Droplets. Dry Technol 2004; 22: 179-190.

[127] FDA. Guidance for Industry, Waiver of in vivo bioavailability and bioequivalence studies for immediate release solid oral dosage forms based on a biopharmaceutics classification system. Cent Drug Eval Res 2015; 1-2.

[128] Ivey JW, Vehring R. The use of modeling in spray drying of emulsions and 
suspensions accelerates formulation and process development. Comput Chem Eng 2010; 34: 1036-1040.

[129] Kaur P, Singh SK, Garg V, et al. Optimization of spray drying process for formulation of solid dispersion containing polypeptide-k powder through quality by design approach. Powder Technol 2015; 284: 1-11.

[130] Guimarães TF, Lanchote AD, Da Costa JS, et al. A multivariate approach applied to quality on particle engineering of spray-dried mannitol. Adv Powder Technol 2015; 26: 1094-1101.

[131] Lebrun P, Krier F, Mantanus J, et al. Design space approach in the optimization of the spray-drying process. Eur J Pharm Biopharm 2012; 80: 226-234.

[132] Dobry DE, Settell DM, Baumann JM, et al. A Model-Based Methodology for SprayDrying Process Development. J Pharm Innov 2009; 4: 133-142.

[133] Ali M, Mahmud T, Heggs PJ, et al. A one-dimensional plug-flow model of a countercurrent spray drying tower. Chem Eng Res Des 2014; 92: 826-841.

[134] Pinto M, Kemp I, Bermingham S, et al. Development of an axisymmetric population balance model for spray drying and validation against experimental data and $\{C F D\}$ simulations. Chem Eng Res Des 2014; 92: 619-634.

[135] Sandler N, Wilson D. Prediction of Granule Packing and Flow Behavior Based on Particle Size and Shape Analysis. J Pharm Sci 2010; 99: 958-968.

[136] ICH. Q6A Specifications: Test Procedures and Acceptance Criteria for New Drug Substance and New Drug Products: Chemical Substances. ICH Harmon Tripart Guidel $1999 ; 35$.

[137] Kerč J, Srčič S. Thermal analysis of glassy pharmaceuticals. Thermochim Acta 1995; 248: 81-95.

[138] Lloyd R. Glass transition and caking of spray-dried lactose. Int J ... 1996; 305-311.

[139] Beever P. Spontaneous Ignition of Milk Powders in a Spray-Drying Plant. J Soc Dairy Technol 1984; 37: 68-71.

[140] Elversson J, Millqvist-Fureby A, Alderborn G, et al. Droplet and particle size relationship and shell thickness of inhalable lactose particles during spray drying. $J$ Pharm Sci 2003; 92: 900-10.

[141] Elversson J, Millqvist-Fureby A. Particle size and density in spray drying-effects of carbohydrate properties. J Pharm Sci 2005; 94: 2049-60.

[142] Wang F-J, Wang C-H. Sustained release of etanidazole from spray dried microspheres prepared by non-halogenated solvents. J Control Release 2002; 81: 263-280.

[143] Schindler A, Harper D. Relationships and Unperturbed Chain Dimensions. 1979; 17: 2593-2599.

[144] Lakowicz JR. Principles of Fluorescence Spectroscopy. Springer Science \& Business Media, 2006. 
[145] Downton GE, Flores-Luna JL, King CJ. Mechanism of stickiness in hygroscopic, amorphous powders. Ind Eng Chem Fundam 1982; 21: 447-451.

[146] ICH Expert Working Group. Impurities: Guideline for Residual Solvents Q3C (R5). Int Conf Harmon Tech Requir Regist Pharm Hum Use 2011; 29.

[147] Santos L, Cordeiro P, Temtem M. Scale-up of Spray Dried Amorphous Solid Dispersions. Eur Indust Pharm 2013; 4-8.

[148] Maa YF, Costantino HR, Nguyen P a, et al. The effect of operating and formulation variables on the morphology of spray-dried protein particles. Pharm Dev Technol 1997; 2: 213-23.

[149] Adhikari B, Howes T, Bhandari BR, et al. Surface Stickiness of Drops of Carbohydrate and Organic Acid Solutions During Convective Drying: Experiments and Modeling. Dry Technol 2003; 21: 839-873.

[150] Maas SG, Schaldach G, Littringer EM, et al. The impact of spray drying outlet temperature on the particle morphology of mannitol. Powder Technol 2011; 213: 2735 . 
Table 1: Factors affecting product and process attributes to be considered during spray drying process development.

\begin{tabular}{|c|c|c|c|}
\hline & Primary factors & Properties to be investigated during process development & References \\
\hline \multirow{16}{*}{ 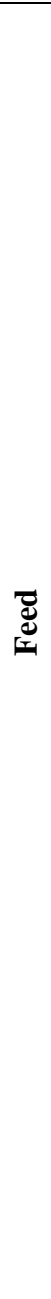 } & $\begin{array}{l}\text { Temperature stability of feed materials on product } \\
\text { stability and process yield }\end{array}$ & $\begin{array}{l}\text { Decomposition temperature, } T_{d e c} \text {, melting point, } T_{m} \text {, and glass transition } \\
\text { temperature, } T_{g}\end{array}$ & {$[24,110,137]$} \\
\hline & $\begin{array}{l}\text { Crystalline/amorphous character of feed materials on } \\
\text { product stability and process yield }\end{array}$ & $\begin{array}{l}T_{g} \text { or } T_{g} \text { shift of starting materials/product. } \\
\text { Theoretical link of molecular weight to glass formation }\end{array}$ & {$[25,26,76]$} \\
\hline & $\begin{array}{l}\text { Hygroscopicity of feed materials on final product } \\
\text { stability and other product specs }\end{array}$ & Equilibrium moisture content, DVS profile & {$[24,91,138]$} \\
\hline & $\begin{array}{l}\text { Chemical incompatibility of feed materials on stability } \\
\text { and product specs }\end{array}$ & Spectroscopic properties such as new or absent peaks & {$[6]$} \\
\hline & $\begin{array}{l}\text { Flammability of materials and any impurities on } \\
\text { process safety }\end{array}$ & $\begin{array}{l}\text { Flash point for volatile materials or the auto-ignition temperature (AIT); cloud } \\
\text { ignition temperature (CIT) and in a solid/semi-solid layer minimum ignition layer } \\
\text { temperature (MILT) }\end{array}$ & [139] \\
\hline & $\begin{array}{l}\text { Physico-chemical and rheological properties on } \\
\text { product structure (particle size, morphology, and } \\
\text { phase composition) }\end{array}$ & $\begin{array}{l}\text { Equilibrium solubility, dispersibility, concentration, viscosity and molecular } \\
\text { weight of components. } \\
\text { Solubility of the materials at the wet bulb temperature, } T_{w b} \text {; Péclet number } \\
\text { affected by the diffusion coefficient and hydrodynamic diameter of the solutes, } d_{H}\end{array}$ & $\begin{array}{l}{[25,76,77,83,84,109,113,} \\
116,140-144]\end{array}$ \\
\hline & Rheological properties on process smooth operation & Feed viscosity & {$[145]$} \\
\hline & $\begin{array}{l}\text { Solvent Toxicity on product safety and process } \\
\text { environmental footprint }\end{array}$ & ICH solvent classification & {$[146]$} \\
\hline & Solvent(s) flammability on process safety & Lower Explosion Limit (LEL) of the solvent system & {$[6,139]$} \\
\hline & $\begin{array}{l}\text { Solvent volatility on process evaporation rate (and } \\
\text { process throughput) and particle formation }\end{array}$ & $\begin{array}{l}\text { Latent heat of vaporization, } \lambda \text {; Boiling Point } T_{\text {boil }} \text { residual solvent in product, } \\
\text { moisture content, } T_{g} \text {, particle phase structure, particle apparent density/porosity }\end{array}$ & $\begin{array}{l}{[3,6,11,12,25,44,64,76} \\
79,89,113,147]\end{array}$ \\
\hline & Material volatility on particle structure and porosity & Latent heat of vaporization $(\lambda)$ & {$[6,41]$} \\
\hline & $\begin{array}{l}\text { Surface activity of materials in solvent system on } \\
\text { product particle architecture }\end{array}$ & $\begin{array}{l}\text { Static/dynamic surface tension and secondary adsorption/diffusion coefficients } \\
\text { revealing surface mobility/self-organisation of feed materials }\end{array}$ & {$[14,82,114,120]$} \\
\hline & $\begin{array}{l}\text { Size \& morphology of primary particles on size and } \\
\text { surface morphology of product particles }\end{array}$ & Morphology of primary particles and product particles & {$[14,38,113]$} \\
\hline & $\begin{array}{l}\text { Concentration of components in the spray drying feed } \\
\text { on process throughput }\end{array}$ & Process throughput & {$[6]$} \\
\hline & $\begin{array}{l}\text { Concentration of components in the spray drying feed } \\
\text { on particle morphology }\end{array}$ & $\begin{array}{l}\text { Droplet stiffness (i.e. rigidity or resistance to deformation) due to high } \\
\text { concentration }\end{array}$ & {$[82]$} \\
\hline & $\begin{array}{l}\text { Presence of air bubbles (aeration) within the feed on } \\
\text { particle porosity }\end{array}$ & Porosity or morphological examination & {$[108]$} \\
\hline
\end{tabular}




\begin{tabular}{|c|c|c|c|}
\hline \multirow{6}{*}{ 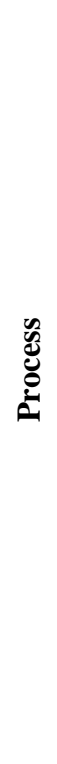 } & $\begin{array}{l}\text { Atomisation mechanism or nozzle orifice diameter on } \\
\text { process smooth operation and particle size }\end{array}$ & Droplet size (or size distribution) and morphological examination of particles & [80] [66] \\
\hline & $\begin{array}{l}\text { Feed flow rate on process throughput and product } \\
\text { quality attributes (particle size and moisture content) }\end{array}$ & $\begin{array}{l}\text { Volumetric feed flow rate, } F \\
\text { Particle size/droplet size } \\
\text { Moisture content }\end{array}$ & {$[132][78]$} \\
\hline & $\begin{array}{l}\text { Air flow rate in a two-fluid atomiser or frequency in } \\
\text { ultrasonic atomiser on particle size, moisture content } \\
\text { and process smooth operation }\end{array}$ & Droplet size (or size distribution), droplet residence time and particle size & [7][103] \\
\hline & $\begin{array}{l}\text { Inlet Temperature, Outlet temperature (resulting from } \\
T_{i n} \text { and } F \text { ) on product structure and process smooth } \\
\text { operation/yield }\end{array}$ & $\begin{array}{l}\text { Evaporation rate } \\
\text { Moisture content or residual solvent content } \\
T_{g} \text { of materials within droplet (material with higher } T_{g} \text { would be less susceptible } \\
\text { to stickiness) } \\
\text { Crystalline/amorphous particle phase structure } \\
\text { Process yield (formation of deposits or degradation by high temperature) } \\
\text { Process thermal efficiency (i.e. energy loss) }\end{array}$ & {$[148][149][88]$} \\
\hline & $\begin{array}{l}\text { Chamber dimensions on particle moisture content, } \\
\text { particle size and process smooth operation }\end{array}$ & $\begin{array}{l}\text { Droplet residence time } \\
\text { Particle moisture content } \\
\text { Particle size } \\
\text { Formation of deposits }\end{array}$ & [7] \\
\hline & Temperature (inlet/outlet) on particle morphology & Péclet number & {$[113][150]$} \\
\hline
\end{tabular}




\section{Figure Legends}

Figure 1: Number of publications on spray dried drug delivery systems classified by route of administration (1990-2016). A) \& B) specifically show the trend for publications focused on oral and pulmonary drug delivery systems respectively.

Figure 2: Spray drying solubility enhancement technologies over the years.

Figure 3: A typical co-current spray dryer layout highlighting the process stages and the main particle transformations expected during spray drying.

Figure 4: Droplet evaporation scheme according to Péclet number concept $(P e=k / 8 D)$. Darker (black) arrows for solvent evaporation rate $(k)$, grey arrows for solute diffusion $(D)$ and dashed arrows for droplet receding surface $(d r / d t)$. Arrow size is proportional to rate of evaporation, diffusion or surface recession. 